Strong Limit Theorems 
Mathematics and Its Applications (Chinese Series)

Managing Editor :

M. HAZEWINKEL

Center for Mathematics and Computer Science,

Amsterdam, The Netherlands 


\section{Strong Limit Theorems}

Lin Zhengyan and Lu Chuanrong

Hangzhou University,

Hangzhou, People's Republic of China

Springer-Science+Business Media, B.V. 
Library of Congress Cataloging in Publication Data

ISBN 978-90-481-4167-8 ISBN 978-94-017-3097-6 (eBook)

DOI 10.1007/978-94-017-3097-6

All Rights Reserved

(C) 1992 by Springer Science+Business Media Dordrecht

Originally published by Kluwer Academic Publishers in 1992

Softcover reprint of the hardcover 1st edition 1992

No part of the material protected by this copyright notice may be reproduced or utilized in any form or by any means, electronic or mechanical, including photocopying, recording, or by any information storage and retrieval system, without written permission from the copyright owners. 
'Et moi, ..., si j'avait su comment en revenir, je n'y serais point alle.'

$$
\text { Jules Verne }
$$

The series is divergent; therefore we may be able to do something with it.

O. Heaviside
One service mathematics has rendered the human race. It has put common sense back where it belongs, on the topmost shelf next to the dusty canister labelled 'discarded nonsense'. Eric T. Bell

Mathematics is a tool for thought. A highly necessary tool in a world where both feedback and nonlinearities abound. Similarly, all kinds of parts of mathematics serve as tools for other parts and for other sciences.

Applying a simple rewriting rule to the quote on the right above one finds such statements as: 'One service topology has rendered mathematical physics ...'; 'One service logic has rendered computer science ...'; 'One service category theory has rendered mathematics ...'. All arguably true. And all statements obtainable this way form part of the raison d'être of this series.

This series, Mathematics and Its Applications, started in 1977. Now that over one hundred volumes have appeared it seems opportune to reexamine its scope. At the time I wrote

\begin{abstract}
"Growing specialization and diversification have brought a host of monographs and textbooks on increasingly specialized topics. However, the 'tree' of knowledge of mathematics and related fields does not grow only by putting forth new branches. It also happens, quite often in fact, that branches which were thought to be completely disparate are suddenly seen to be related. Further, the kind and level of sophistication of mathematics applied in various sciences has changed drastically in recent years: measure theory is used (non-trivially) in regional and theoretical economics; algebraic geometry interacts with physics; the Minkowsky lemma, coding theory and the structure of water meet one another in packing and covering theory; quantum fields, crystal defects and mathematical programming profit from homotopy theory; Lie algebras are relevant to filtering; and prediction and electrical engineering can use Stein spaces. And in addition to this there are such new emerging subdisciplines as 'experimental mathematics', 'CFD', 'completely integrable systems', 'chaos, synergetics and largescale order', which are almost impossible to fit into the existing classification schemes. They draw upon widely different sections of mathematics."
\end{abstract}

By and large, ali this still applies today. It is still true that at first sight mathematics seems rather fragmented and that to find, see, and exploit the deeper underlying interrelations more effort is needed and so are books that can help mathematicians and scientists do so. Accordingly MIA will continue to try to make such books available.

If anything, the description I gave in 1977 is now an understatement. To the examples of interaction areas one should add string theory where Riemann surfaces, algebraic geometry, modular functions, knots, quantum field theory, Kac-Moody algebras, monstrous moonshine (and more) all come together. And to the examples of things which can be usefully applied let me add the topic 'finite geometry'; a combination of words which sounds like it might not even exist, let alone be applicable. And yet it is being applied: to statistics via designs, to radar/sonar detection arrays (via finite projective planes), and to bus connections of VLSI chips (via difference sets). There seems to be no part of (so-called pure) mathematics that is not in immediate danger of being applied. And, accordingly, the applied mathematician needs to be aware of much more. Besides analysis and numerics, the traditional workhorses, he may need all kinds of combinatorics, algebra, probability, and so on.

In addition, the applied scientist needs to cope increasingly with the nonlinear world and the extra 
mathematical sophistication that this requires. For that is where the rewards are. Linear models are honest and a bit sad and depressing: proportional efforts and results. It is in the nonlinear world that infinitesimal inputs may result in macroscopic outputs (or vice versa). To appreciate what I am hinting at: if electronics were linear we would have no fun with transistors and computers; we would have no TV; in fact you would not be reading these lines.

There is also no safety in ignoring such outlandish things as nonstandard analysis, superspace and anticommuting integration, $p$-adic and ultrametric space. All three have applications in both electrical engineering and physics. Once, complex numbers were equally outlandish, but they frequently proved the shortest path between 'real' results. Similarly, the first two topics named have already provided a number of 'wormhole' paths. There is no telling where all this is leading - fortunately.

Thus the original scope of the series, which for various (sound) reasons now comprises five subscrics: white (Japan), yellow (China), red (USSR), blue (Eastern Europe), and green (everything else), still applies. It has been enlarged a bit to include books treating of the tools from one subdiscipline which are used in others. Thus the series still aims at books dealing with:

- a central concept which plays an important role in several different mathematical and/or scientific specialization areas;

- new applications of the results and ideas from one area of scientific endeavour into another;

- influences which the results, problems and concepts of one field of enquiry have, and have had, on the development of another.

To quite a large extent limit theorems (or laws of large numbers) are what makes statistics applicable. Particularly important are strong limit theorems. This is well known. Still I was surprised to find that 2651 articles and books have appeared with the phrase 'strong limit theorems' in title, abstract, keyword list, or table of contents. And most of these appeared after 1981, which appears to be the last time that the ficld was surveyed as a whole.

In this volume the authors survey the results obtained in strong limit theory in the last 10 years or so, including some of their own work. It seems to me a most useful thing to have around for every mathematician or statistician who just might need a strong limit related result that goes beyond the standard ones.

The shortest path between two truths in the real domain passes through the complex domain.

$$
\text { J. Hadamard }
$$

La physique ne nous donne pas seulement l'occasion de résoudre des problèmes ... elle nous fait pressentir la solution.

$$
\text { H. Poincaré }
$$

Bussum, 10 February 1992
Never lend books, for no one ever returns them; the only books I have in my library are books that other folk have lent me.

\section{Anatole France}

The function of an expert is not to be more right than other people, but to be wrong for more sophisticated reasons.

David Butler

Michiel Hazewinkel 


\section{Preface}

Strong approximation and strong convergence methodologies have been very active areas of research in probability theory during the past two decades. The 1981 monograph of M.Csörgo" and P. Révész Strong Approximations in Probability and Statistics sums up the basic results of this kind up to the beginning of the 1980s. In the introduction to their book, the authors pointed out possible directions for further research, such as multitime parameter processes and processes in higher-dimensional Euclidean space (or Banach space), as well as the case of nonindependent and /or non-identically distributed random variables.

In recent years, many results of Csörgö and Révész ( 1981) have been generalized and improved to a great extent. Limit properties of a Wiener process have been continuously studied extensively and deeply by some authors, and limit results of the increments of partial sums of a sequence of random variables have been sharpened and generalized to the case of independent, but not necessarily identically distributed random variables by Z.Y. Lin and Q. M. Shao. Path properties of some Gaussian processes related to a Wiener process have been also investigated. This monograph aims to provide an overview of this work.

We are deeply indebted to Professor M. Csörgó (Carleton University, Canada) and can only say that this monograph could never have been written without his encouragement. Our best thanks are due to Dr. Q. M. Shao whose comments greatly improved the book. Our thanks go also to B. Chen, Z. W. Cai and Z. G. Su for their helpful suggestions.

Lin Zhengyan

Lu Chuanrong

Hangzhou University, April 1992 


\section{Contents}

Series Editor's Preface v v

Preface vii

1. The Increments of a Wiener and Related Gaussian Processes

1.1 How Large Are the Increments of a Wiener Process?........ 1

1.2 Some Inferior Limit Results for the Increments of

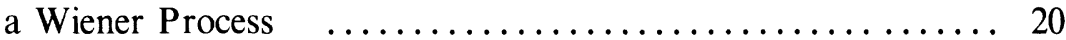

1.3 Further Discussion for Increments of a Wiener Process ....... 27

1.4 How Large Are the Increments of a Two-Parameter

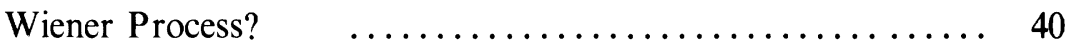

1.5 The Increments of a Non-Stationary Gaussian Process ....... 62

2. The Increments of Partial Sums of Independent

Random Variables ........................ 72

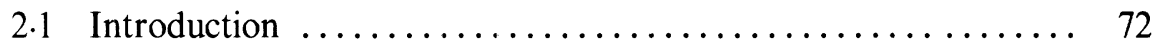

2.2 How Large Are the Lag Sums? . . . . . . . . . . . . 76

2.3 How Large Are the Csörgö-Révész Increments? ........... 86

2.4 On the Increments Without Moment Hypotheses .......... 100

2.5 How Small Are the Increments of Partial Sums of Independent R. V.'s ? ..................... 112

2.6 A Study of Partial Sums with the Help

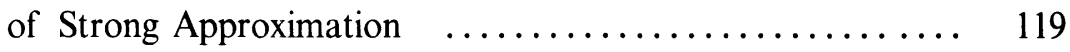

3. Strong Laws of the Processes Generated by Infinite Dimensional Ornstein-Uhlenbeck Processes ......... 129

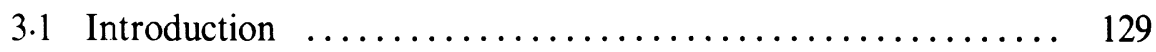

3.2 Partial Sum Process $\ldots \ldots \ldots \ldots \ldots \ldots \ldots \ldots \ldots \ldots . \ldots \ldots \ldots$

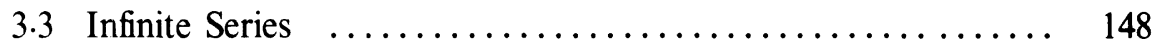


$3.4 l^{2}$-Norm Squared Process $\ldots \ldots \ldots \ldots \ldots \ldots \ldots \ldots \ldots \ldots \ldots \ldots \ldots \ldots$

3.5 Two-Parameter Gaussian Process with Kernel ........... 173

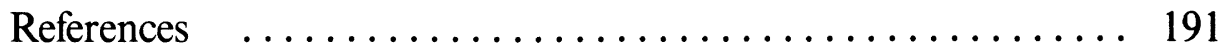

